\title{
On the hydrogen desorption entropy change of modified $\mathrm{MgH}_{2}$
}

\author{
Jie Cui ${ }^{1,2}$, Liuzhang Ouyang ${ }^{2}$, Hui Wang ${ }^{2}$, Xiangdong Yao ${ }^{3,4} *$, Min Zhu ${ }^{2,4 *}$ \\ ${ }^{1}$ Analysis and Test Center, South China University of Technology, Guangzhou, 510640, P. R. \\ China. \\ ${ }^{2}$ School of Material Science and Engineering, South China University of Technology, \\ Guangzhou, 510640, P. R. China. \\ ${ }^{3}$ School of Natural Sciences, Griffith University, Nathan, QLD 4111, Australia. \\ ${ }^{4}$ Australia-China Joint Laboratory for Energy \& Environmental Materials, Griffith University, \\ Nathan, QLD 4111, Australia
}

\begin{abstract}
:
Reducing hydrogen desorption temperature $\left(T_{d}\right)$ is a current challenge for application of Mg-based hydrogen storage alloys. The equilibrium $T_{d}$ is directly determined by the thermodynamics, characterized by the enthalpy $(\Delta H)$ and the entropy $(\Delta S)$, of hydrogen desorption reaction of $\mathrm{MgH}_{2}$. While the change of $\Delta H$ has been proved due to the size effect and alloying effect, the $\Delta S$ is customary considered as entropy of $\mathrm{H}_{2}$, being a constant of $130.5 \mathrm{Jmol}^{-1} \cdot \mathrm{K}^{-1}$. Very recently, however, the $\Delta S$ is experimentally reported to change in some cases as well. In this work, for the first time, we proposed a model to illustrate theoretically that the vary of $\Delta S$, which significantly influences the $T_{d}$, of $\mathrm{MgH}_{2}$ with the changing particle/grain size, covering catalyst on surface and forming solid solution of $\mathrm{MgH}_{2}$ that facilitates the hydrogen molecule dissociation. The model is supported by the experimental results.
\end{abstract}

Key words: $\mathrm{MgH}_{2}$; desorption; entropy; size effect; catalysis

\section{Introduction}

The difficulty in hydrogen storage is heavily hindering the hydrogen energy application that is an important strategy to solve the critical problems such as fossil fuel depletion, environmental pollution and global climate change ${ }^{[1]}$. Over the tremendous efforts devoted in 
the last decades, hydrides of high hydrogen storage capacity have been developed, however, they are generally difficult to release hydrogen in a fast rate under moderate conditions ${ }^{[2]}$. In a particular example, $\mathrm{MgH}_{2}$ requires a temperature of $300^{\circ} \mathrm{C}$ to desorb $\mathrm{H}_{2}$ although it has significant merits of high hydrogen capacity, excellent reversibility and low cost. Nevertheless, substantial progress has been achieved in improving dehydrogenation kinetics of Mg-based hydrides through various strategies and fast hydrogen absorption at an ambient temperature can be realized in recent years ${ }^{[3]}$.

However, hydrogen desorption of $\mathrm{MgH}_{2}$ still requires high temperature or low $\mathrm{H}_{2}$ pressure, which is determined by the dehydrogenation thermodynamics ${ }^{[4]}$ expressed in the following equation according to van't Hoff plot ${ }^{[5]}$ :

$$
T_{d}=\Delta H / \Delta S
$$

Where $T_{d}$ is hydrogen desorption temperature, $\Delta H$ and $\Delta S$ are the enthalpy and entropy of hydrogen desorption, respectively. Typically, the $\Delta H$ and $\Delta S$ are about $75 \mathrm{~kJ} \mathrm{~mol}^{-1}$ and 130.5 $\mathrm{Jmol}^{-1} \cdot \mathrm{K}^{-1}$ for a bulk $\mathrm{MgH}_{2}$ system, respectively ${ }^{[3]}$. Accordingly, the $T_{d}$ is calculated to be $289^{\circ} \mathrm{C}$ under $1 \mathrm{~atm} \mathrm{H}_{2}$ pressure, which is too high for $\mathrm{Mg}$ to be used practically, in particular for mobile applications. Thus, it is of great interesting to develop new strategies to tune the thermodynamics by destabilizing $\mathrm{MgH}_{2}{ }^{[6]}$.

Theoretically, it is predicted that the $\Delta H$ can be reduced obviously when the size of $\mathrm{MgH}_{2}$ is reduced to several nanometer, ${ }^{[7]}$ for example, to $63 \mathrm{kJmol}^{-1}$ at the size of $0.9 \mathrm{~nm}{ }^{[8]}$ and the corresponding $T_{d}$ can be remarkably reduced to $\sim 200{ }^{\circ} \mathrm{C}$ if the $\Delta S$ is considered as a constant of $\sim 130.5 \mathrm{Jmol}^{-1} \cdot \mathrm{K}^{-1}$. These predictions triggered intensive experimental investigations. For example, Paskevicius et al, produced $\mathrm{Mg} / \mathrm{MgH}_{2}$ nano-particles with a size of $15 \sim 40 \mathrm{~nm}$ by the mechanochemical method, and the $\Delta H$ and the $\Delta S$ are measured to be $74.75 \pm 0.42 \mathrm{~kJ} \mathrm{~mol}^{-1} \mathrm{H}_{2}$ and $129.6 \mathrm{~J} \mathrm{~mol}^{-1} \mathrm{H}_{2}$, respectively ${ }^{[9]}$.

Almost all the theoretical and experimental studies about the thermodynamics of hydrogen desorption are based on a general regarding of a constant $\Delta S$. However, there are a few examples shown that the $\Delta S$ is variable in recent research ${ }^{[7,10]}$. For instance, a significant decrease of the $\Delta H\left(63.8 \pm 0.5 \mathrm{~kJ} \mathrm{~mol}^{-1}\right)$ and the $\Delta S\left(117.2 \pm 0.8 \mathrm{Jmol}^{-1} \mathrm{~K}^{-1}\right)$ was reported in $\mathrm{MgH}_{2}$ nanoparticles with a size of less than $3 \mathrm{~nm}$ by hydrogenation of $\mathrm{Bu}_{2} \mathrm{Mg}$ inside the pores of a carbon scaffold ${ }^{[7]}$. Although the $\Delta H$ is greatly decreased, the decrease of the $T_{d}$ was only 
$11^{\circ} \mathrm{C}$ because of the counter effect of the decreased $\Delta S$. Buckley et al ${ }^{[9]}$ synthesized $\mathrm{MgH}_{2}$ nanoparticles embedded in a $\mathrm{LiCl}$ salt matrix by a mechanochemical method. They found the $\Delta H$ decreased from $74.06 \pm 0.42 \mathrm{~kJ} \mathrm{~mol}^{-1}$ for the bulk $\mathrm{MgH}_{2}$ to $71.22 \pm 0.49 \mathrm{~kJ} \mathrm{~mol}^{-1}$ for the $\mathrm{MgH}_{2}$ nanoparticles of about $7 \mathrm{~nm}$. However, the $\Delta S$ also decreased from $133.4 \pm 0.7$ $\mathrm{Jmol}^{-1} \mathrm{~K}^{-1}$ to $129.6 \pm 0.8 \mathrm{Jmol}^{-1} \mathrm{~K}^{-1}$. Similarly, due to the decrease in the $\Delta \mathrm{S}$, the decrease of $T_{d}$ is much less than that calculated from the sole $\Delta H$ change. In our previous work, it was firstly observed that, the $\Delta S$ could be increased to $136.3 \mathrm{Jmol}^{-1} \mathrm{~K}^{-1}$ in a core-shell structured $\mathrm{Mg}$ with Ti-based catalyst as the shell ${ }^{[11]}$. Besides that, in $\mathrm{Mg}_{90} \mathrm{In}_{5} \mathrm{Cd}_{5}$ ternary solid solution alloy, $\Delta S$ is 154.8 $\mathrm{Jmol}^{-1} \mathrm{H}_{2} \mathrm{~K}^{-1}$, which is much higher than the values for pure $\mathrm{Mg} 138.9 \mathrm{Jmol}^{-1} \mathrm{H}_{2} \mathrm{~K}^{-1}$ in Lu's report ${ }^{[12]}$. The above results indicate that it is possible to alter $\Delta \mathrm{S}$ in both directions, i.e. either larger or smaller. However, the $\Delta S$ was regarded as constant in general and the physical nature is still unclear for the $\Delta S$ changes in those situation. Although it was reported that the decrease of $\Delta \mathrm{S}$ in nano $\mathrm{Mg}$ system may originate from statistical errors in Van 't Hoff plots $^{[13,14]}$. The fact of the desorption/absorption pressure increasing during the size reduction can not be neglected which state the $\Delta \mathrm{S}$ may altered in the modified $\mathrm{Mg} / \mathrm{MgH}_{2}$ system. Hence, it is very significant to figure out the nature for the $\Delta S$ change by establishing theoretical models, and this is also important for exploring strategy to tuning thermodynamics of hydrogen storage reaction.

In this paper, we develop a model for the dehydrogenation entropy $\Delta S$ of $\mathrm{MgH}_{2}$ modified in particle/grain size, composition by forming solid solutions, and surface by coating catalyst. It can be predicted, from this model, that the dehydrogenation entropy would change, e.g. be less than $120.1 \mathrm{Jmol}^{-1} \mathrm{H}_{2} \mathrm{~K}^{-1}$ at the particle/grain size of $3 \mathrm{~nm}$. The theoretical calculations from this model are consistent with the experimental results.

\section{Statistical concept in dehydrogenation entropy of $\mathrm{MgH}_{2}$}

According to the Boltzmann entropy expansion, the system's entropy $(S)$ can be expressed as the $\operatorname{Eq}(2)^{[15]}$.

$$
S=k \ln W_{B}=N k \ln \frac{Z}{N}+\frac{U}{T}+N k
$$

Where $k$ is Boltzmann constant, $W_{B}$ is the number of the most probable microstates, $N$ is number of the atoms in the system, $Z$ is the partition function, $U$ is the internal energy and $T$ is 
the temperature. Indeed, the system's entropy is the sum of various independence movements (translation, rotation, vibration, electronic movement and electronic anti-nuclear movement) of particles. In our case, the contribution of electronic movement and electronic anti-nuclear movement to the system's entropy can be ignored because they are in ground state under general temperatures. Hence, the $S$ can be comprised of three contributions $\left(S_{t}, S_{r}\right.$ and $\left.S_{v}\right)$ as indicated in supporting information $\mathrm{I}$, where $S_{t}, S_{r}$ and $S_{v}$ stands for the entropy of translation, rotation and vibration, respectively.

According to the equation for $S_{t}, S_{r}$ and $S_{v}$ as shown in supporting information I, it can be found the number of atoms in the system is one of the key factor, and the number of the atoms should be 1 and $3 \mathrm{~mol}$ for a system of $1 \mathrm{~mol} \mathrm{Mg}$ and $\mathrm{MgH}_{2}$, respectively. Hence, $S_{M g}$ and $S_{\mathrm{MgH}_{2}}$ can be expressed as Eq (3) and (4), respectively, where $N_{A}$ is Avogadro's constant, $h$ is the Planck constant, $\mathbb{H}_{r}$ stands for rotational factor, $\sigma$ is the symmetry number, $\mathbb{A}_{v}$ stands for vibrational factor, $V$ is the volume, $m$ is the mass.

$$
\begin{gathered}
S_{M g}=N_{A} k \ln \frac{V_{M g}\left(2 \pi m_{M g} k T\right)^{3 / 2}}{N_{A} h^{3}}+\frac{11}{2} N_{A} k+N_{A} k \ln \left(T / \Theta_{r_{M g}} \cdot \sigma\right)+N_{A} k \ln \left[\left(1-e^{-\Theta_{v_{M g}} / T}\right) / N_{A}\right]+ \\
N_{A} k \mathbb{H}_{v_{M g}} T^{-1}\left(e^{\Theta_{v_{M g}} / T}-1\right)^{-1} \\
S_{M g H_{2}}=3 N_{A} k \ln \frac{V_{\mathrm{MgH}_{2}}\left(2 \pi m_{M g H_{2}} k T\right)^{3 / 2}}{N_{A} h^{3}}+\frac{33}{2} N_{A} k+3 N_{A} k \ln \left(T / \mathbb{H}_{r_{M g H_{2}}} \cdot \sigma\right) \\
+3 N_{A} k \ln \left[\left(1-e^{-\Theta_{v_{M g H_{2}} / T}}\right) / 3 N_{A}\right]+3 N_{A} k \mathbb{H}_{v_{M g H_{2}}} T^{-1}\left(e^{\Theta_{v_{M g H_{2}}} / T}-1\right)^{-1}
\end{gathered}
$$

\section{The effect of nanosizing on the dehydrogenation entropy of $\mathrm{MgH}_{2}$}

Obviously, one of the most remarkable structural features in nano materials is that there are huge interfaces and higher specific surface area. Thus, there is an excess volume $(\Delta V)$ in nano materials in comparison with the volume of perfect crystal in bulk materials $\left(V_{0}\right)$. The volume in nanomaterials can be described as $V^{\prime}=V_{0}(1+\Delta V)$. According to the model of excess volume in Song's work ${ }^{[16]}$, the volume ratio of the nano to bulk material can be expressed as Eq (5), where $d$ is the diameter of the equivalent spherical volume of nanoparticles or nano-crystals and $\delta$ is thickness of the grain boundary.

$$
\frac{V^{\prime}}{V_{0}}=\frac{0.8\left[d^{3}-(d-\delta)^{3}\right]+d^{3}}{d^{3}}
$$

Hence, as shown in supporting information $\mathrm{I}, S_{t}$ of $\mathrm{Mg}$ and $\mathrm{MgH}_{2}$ are both increased due to 
the increase of $V^{\prime}$ in nano-size $\mathrm{Mg} / \mathrm{MgH}_{2} . \Delta S_{t_{M g}}$ and $\Delta S_{t_{M g H_{2}}}$ can be expressed as Eq (6) and Eq (7), respectively, where $R$ is molar gas constant.

$$
\begin{aligned}
\Delta S_{t_{M g}} & =R \ln \frac{V_{M g}^{\prime}}{V_{0_{M g}}} \\
\Delta S_{t_{M g H_{2}}} & =3 R \ln \frac{V_{\mathrm{MgH}}^{\prime}}{V_{0_{\mathrm{MgH}}}}
\end{aligned}
$$

$S_{r}$ is not affected by the change of volume, thus the $\Delta S_{r_{M g}}$ and $\Delta S_{r_{M_{g H}}}$ can be neglected. Besides, the average interatomic distance is increased from $r_{0}$ in bulk material to $r^{\prime}$ in nano material (corresponding to the volume change), which can affect the $S_{v}$ both in $\mathrm{Mg}$ and $\mathrm{MgH}_{2}$. To simplify the calculations, the volume expansion is supposed to be equivalently as the interatomic distance increase as shown in supporting information II. Hence, $\Delta S_{t_{M g}}$ and $\Delta S_{t_{M H_{2}}}$ can be expressed as Eq (7) and Eq (8), respectively.

$$
\begin{aligned}
\Delta S_{v_{\mathrm{Mg}}} & =R \ln \frac{r_{\mathrm{Mg}}^{\prime}}{r_{0 \mathrm{Mg}}} \\
\Delta S_{v_{\mathrm{MgH}}} & =3 R \ln \frac{r_{\mathrm{MgH}}^{\prime}}{r_{0 \mathrm{MgH}_{2}}}
\end{aligned}
$$

The entropy of the dehydriding reaction of $\mathrm{MgH}_{2}$ can be short standed as $\Delta S$, it can be described as Eq (9)

$$
\Delta S=S_{M g}+S_{H_{2}}-S_{M g H_{2}}
$$

For the bulk $\mathrm{Mg} / \mathrm{MgH}_{2}, \Delta S_{\text {bulk }}$ can be calculated as,

$$
\Delta S_{\text {bulk }}=S_{M g}^{\theta}+S_{\mathrm{H}_{2}}^{\theta}-S_{M g H_{2}}^{\theta}
$$

When considering nano-size $\mathrm{Mg}$ and $\mathrm{MgH}_{2}$, the excess volume and change of average interatomic distance should be taken account. Hence, $\Delta S_{\text {nano }}$ can be descried as Eq (11),

$$
\Delta S_{n a n o}=\left(S_{M g}^{\theta}+S_{H_{2}}^{\theta}-S_{M g H_{2}}^{\theta}\right)+\left(R \ln \frac{V_{M g}^{\prime}}{V_{0_{M g}}}+R \ln \frac{r_{\mathrm{Mg}}^{\prime}}{r_{0 \mathrm{Mg}}}-3 R \ln \frac{V_{\mathrm{MgH}_{2}}^{\prime}}{V_{0 \mathrm{MgH}_{2}}}-3 R \ln \frac{r_{\mathrm{MgH}_{2}}^{\prime}}{r_{0 \mathrm{MgH}_{2}}}\right)
$$

For the convenience of calculations, the same ratio of excess volume is considered in $\mathrm{Mg}$ and $\mathrm{MgH}_{2}\left(\frac{V_{M g}^{\prime}}{V_{0_{M g}}}=\frac{V_{\mathrm{MgH}_{2}}^{\prime}}{V_{0_{\mathrm{MgH}_{2}}}}=\frac{V^{\prime}}{V_{0}}\right)$. Accordingly, the same increase of average inter atomic distance $\left(\frac{r_{\mathrm{Mg}}^{\prime}}{r_{\mathrm{OMg}}}=\frac{r_{\mathrm{MgH}}^{\prime}}{r_{\mathrm{OMgH}}}=\frac{r^{\prime}}{r_{0}}=\sqrt[3]{\frac{V^{\prime}}{V_{0}}}\right)$ was taken into account. Hence, $\Delta S_{\text {nano }}$ can be derived as $\mathrm{Eq}(12)$.

$$
\Delta S_{\text {nano }}=\Delta S_{\text {bulk }}-\frac{8}{3} R \ln \frac{0.8\left[d^{3}-(d-\delta)^{3}\right]+d^{3}}{d^{3}}
$$

It can be found that $\Delta S_{n a n o}$ is decreased with the partilce/grain size as indicated in surpporting information III. This can also explain the nature of the enthalpy entropy 
correlations as mentioned again several times recently in 'compensation effects' which were reported in other systems ${ }^{[17,18]}$. And it can be easily understand a weakening of intermolecular bonds (related to the enthalpy) which leads to an increase of the configurational freedom and hence a smaller degree of ordering in the system (related to the entropy). The reduction of the entropy significantly increases the $T_{d}$, although the size effect can lower desorption $\Delta H$ significantly and decreases $T_{d}$ as reported in Dresselhaus's work ${ }^{[19]}$. Thus, the $T_{d}$ change is much less due to the effect of size reduction on the entropy. As shown in the supporting information III, combining the size effect on both $\Delta H$ and $\Delta S$, the $T_{P_{e q}=1 \text { atm }}$ is predicted to only lower to $160^{\circ} \mathrm{C}$ when $d$ is $3 \mathrm{~nm}$, while it is $124^{\circ} \mathrm{C}$ by ignoring the effect of $\Delta S$.

\section{The effect of solid solution formation on dehydrogenation entropy of $\mathrm{MgH}_{2}$}

The formation of Mg-based solid solution, can probably alter the dehydrogenation enthalpy and entropy change of the systems with an acceptable loss of capacity ${ }^{[20,21]}$. Usually, the change of the enthalpy is highly recognized in Mg based solid solution, such as Mg-In ${ }^{[18]}$, $\mathrm{Mg}-\mathrm{Al}{ }^{[22]}$ and Mg-Al-Li system ${ }^{[19]}$. Lately, the negligible change of the entropy is also noticed. The $\Delta S$ are 140.0 and $138.6 \mathrm{Jmol}^{-1} \mathrm{H}_{2} \mathrm{~K}^{-1}$ in 5 at. $\%$ and 10 at. $\% \mathrm{Al}$ supersaturated $\mathrm{Mg}$-Al solid solutions, respectively ${ }^{[23]}$. Thus, the configurationally entropy contributed to dehydrogenation entropy can no longer be ignored.

For solid solution constituted of A and B elements, suppose the atom concentration of A and B are $x_{A}$ and $x_{B}$ mol, respectively, and the sum of $x_{A}$ and $x_{B}$ is 1 mol. Hence, the combination of atom B in A-B solid solution should be $\mathrm{C}_{\left(x_{A}+x_{B}\right) \cdot N_{A}}^{x_{*} \cdot N_{A}}$ as shown in Eq (13).

$$
\mathrm{C}_{\left(x_{A}+x_{B}\right) \cdot N_{A}}^{x_{B} \cdot N_{A}}=\frac{\left[\left(x_{A}+x_{B}\right) \cdot N_{A}\right] !}{\left[\left(x_{A} \cdot N_{A}\right) !\right] \cdot\left[\left(x_{B} \cdot N_{A}\right) !\right]}
$$

Hence, the increase of configuration entropy $\left(\Delta S_{A B}\right)$ contributed by the solid solution can be derived as $\mathrm{Eq}(14)$.

$$
\Delta S_{\mathrm{AB}}=-R\left(x_{A} \cdot \ln x_{A}+x_{B} \cdot \ln x_{B}\right)
$$

For the Mg-based Mg-B binary solid solution, supposing it completely reversible during hydriding/dehydriding and the amount of solution element $x_{B}$ being between 0 and 0.5 $\left(0 \leq x_{B} \leq 0.5\right)$, the hydriding/dehydriding reaction can be described as $\operatorname{Eq}(15)$.

$$
\operatorname{Mg}_{\left(1-x_{B}\right)} \mathrm{B}_{x_{B}}+\left(1-x_{B}\right) \mathrm{H}_{2} \leftrightarrow\left(1-x_{B}\right) \mathrm{MgH}_{2}+x_{B} \mathrm{~B}
$$

Here, the dehydriding entropy $(\Delta S)$ for per mol $\mathrm{H}_{2}$ should be modified as $\mathrm{Eq}(16)$. 


$$
\Delta S=\left[S_{\mathrm{Mg}_{\left(1-x_{B}\right)} \mathrm{B}_{x_{B}}}+\left(1-x_{B}\right) S_{\mathrm{H}_{2}}-\left(1-x_{B}\right) S_{\mathrm{MgH}_{2}}-x_{B} S_{\mathrm{B}}\right] /\left(1-x_{B}\right)
$$

Hence, as indicated in supporting information IV, the $\Delta S$ can be derived as Eq (17). It can be found $\Delta S$ increases with the solubility in Mg-based solid solution alloys as shown in Fig. 2. The entropy increasing significantly decreases the $T d$.

$$
\Delta S=\Delta S_{b u l k}-R\left[\frac{x_{B}}{\left(1-x_{B}\right)} \cdot \ln x_{B}+\ln \left(1-x_{B}\right)\right]
$$

\section{The effect of coating catalyst on dehydrogenation entropy of $\mathrm{MgH}_{2}$}

When $\mathrm{MgH}_{2}$ desorbs hydrogen, the $\mathrm{H}$ atoms will occupied surface of the $\mathrm{Mg} / \mathrm{MgH}_{2}$ particles. These $\mathrm{H}$ atoms would change the surface status and contribute to the $\Delta \mathrm{S}$, depending on the $\mathrm{H}$ concentration. Besides that, Mulder et al reported that a surprising result that substantial amounts of $\mathrm{H}$ dissolve in the $\mathrm{Mg} \alpha$-phase by neutron diffraction. ${ }^{[24]}$. And that also prompted them to reanalyze previously obtained data on $\mathrm{Nb}$ - and $\mathrm{V}$-catalyzed $\mathrm{MgH}_{2}$ reported earlier. They also find the amounts of $\mathrm{H}$ dissolve is much larger than the un-catalyzed $\mathrm{Mg} / \mathrm{MgH}_{2}$ system which lead to the deviations in the entropy of catalyzed $\mathrm{Mg} / \mathrm{MgH}_{2}$ system. Hence, in the catalyzed $\mathrm{Mg} / \mathrm{MgH}_{2}$ system, the effect of catalyst cannot be ignored any more. Fig. 4 is the schematic of dissociated $\mathrm{H}$ atom in different modified $\mathrm{MgH}_{2}$ systems, being with non-catalyst, doping catalyst and covered catalyst. As shown in Fig. 4a, due to the high activation energy $\left(E_{A}\right)$ of $\mathrm{H}_{2}$ dissociation in pure $\mathrm{Mg} / \mathrm{MgH}_{2}$, the amount of dissociated $\mathrm{H}$ is very few at ambient temperature. With the catalysts doping, as shown in Fig. 4b, due to the low $E_{A}$ of $\mathrm{H}_{2}$ dissociation on the surface of catalysts, the amount of dissociated $\mathrm{H}$ is higher than that in pure $\mathrm{Mg} / \mathrm{MgH}_{2}$. Especially, in the catalyst covered core-shell structured system, as schematically shown in Fig. 4c, the covered catalyst enables high concentration of dissociated $\mathrm{H}$ on the surface layer as reported in Mg-Ti systems ${ }^{[11]}$, which is supposed to change the $\Delta S$.

Here, taking $\mathrm{C}$ as catalyst for short, $x_{\mathrm{C}}$ and $x_{H}$ mol as the amount of catalyst and dissociated $\mathrm{H}$, respectively, the dehydriding $\Delta S$ for per $\mathrm{mol} \mathrm{H}_{2}$ in $\mathrm{Eq}$ (9) should be modified as

$$
\Delta S=S_{M g-C-H}+\left(1-x_{C}-\frac{x_{H}}{2}\right) \cdot S_{H_{2}}-S_{M g H_{2}-C} /\left(1-x_{C}-\frac{x_{H}}{2}\right)
$$

For the core-shell structured Mg-C system, $S_{M g-C-H}$ and $S_{M H_{2}-C}$ can be affected by the covered catalyst and dissociated $\mathrm{H}$. And this is depended much on the structure of the catalyst and its activation energy during $\mathrm{H}_{2}$ dissociation. As indicated in Supporting information $\mathrm{V}$ in 
detail, $\Delta S$ can be obtained as shown in $\operatorname{Eq}(19)$.

$$
\Delta S=\frac{\left(1-x_{C}\right) \cdot S_{M g}^{\theta}+x_{H} \cdot S_{H}^{\theta}-R\left[\frac{x_{H}}{x_{C}} \cdot \ln \frac{x_{H}}{x_{C}}+\left(1-\frac{x_{H}}{x_{C}}\right) \cdot \ln \left(1-\frac{x_{H}}{x_{C}}\right)\right]+\left(1-x_{C}-\frac{x_{H}}{2}\right) \cdot S_{H_{2}}^{\theta}-\left(1-x_{C}\right) \cdot S_{M g H_{2}}^{\theta}}{\left(1-x_{C}-\frac{x_{H}}{2}\right)}
$$

Taking Mg-Ti system in our repored work ${ }^{[11]}$ as an example, the $x_{\mathrm{C}}$ of Ti catalyst is about 0.1 mol and the covered layer of Ti is about $5 \sim 10 \mathrm{~nm}$. Here, we assume the average thickness $(\varepsilon)$ of $\mathrm{Ti}$ is $7.5 \mathrm{~nm}$. We suppose every $\mathrm{Ti}$ atom on the extreme surface act as the catalytic active center which can induce one hydrogen molecule dissociated. Hence, $x_{H}$ can be obtained by getting the amount of Ti atom on the extreme surface. As shown in Supporting information V, the value of $x_{\mathrm{H}}$ in Mg-Ti system is $0.00311 \mathrm{~mol}$. Taking the corresponding values into Eq (19), the value caculated in $\mathrm{Mg}$-Ti system is $132.3 \mathrm{Jmol}^{-1} \mathrm{H}_{2} \mathrm{~K}^{-1}$ which is $1.8 \mathrm{Jmol}^{-1} \mathrm{H}_{2} \mathrm{~K}^{-1}$ larger than the pure $\mathrm{Mg} / \mathrm{MgH}_{2}$. This entropy increasing can lower the $T_{d}$.

\section{Validate the model using existing experimental data}

In short, $\Delta S$ decreases with the particle size of $\mathrm{Mg} / \mathrm{MgH}_{2}$, and increases with the solubility in Mg-based solid solution alloy. It also increases with the concentration of dissociated $\mathrm{H}$ on the surface of $\mathrm{Mg} / \mathrm{MgH}_{2}$ particles which depends on the activatity of catalyst on $\mathrm{H}_{2}$ dissociation.

The dehydriding $\Delta \mathrm{S}$ data derived from our experimental nano-size $\mathrm{Mg}$ and many nano-size Mg-based systems from other groups ${ }^{[7,9,25]}$ are given in Table 1. As shown in Fig.1, our experimental data marked as filled circle and other groups data marked as hollow circular, pentacle and box are consistent with the calculated result. The results of the dehydriding $\Delta \mathrm{S}$ reduced with the particle size (ranging from $15-100 \mathrm{~nm})^{[26]}$ also match with our calculation model. Anyway, as discussed above, the $\Delta \mathrm{S}$ decreases substantially with the particle size due to the size effect only when the particle size reduces to very small. Thus, the decrease of $T_{d}$ is not significantly which is in conformity with the reported works.

Taking $\mathrm{Mg}-\mathrm{Al}\left(\mathrm{Mg}_{0.95} \mathrm{Al}_{0.5}\right.$ and $\left.\mathrm{Mg}_{0.9} \mathrm{Al}_{0.1}\right)$ as example for solid solutions ${ }^{[19]}$, calculated $\Delta S$ of $\mathrm{Mg}_{0.95} \mathrm{Al}_{0.5}$ and $\mathrm{Mg}_{0.9} \mathrm{Al}_{0.1}$ are 132.2 and $133.5 \mathrm{Jmol}^{-1} \mathrm{H}_{2} \mathrm{~K}^{-1}$ which are 1.7 and $3.0 \mathrm{Jmol}^{-1} \mathrm{H}_{2} \mathrm{~K}^{-1}$ higher than pure $\mathrm{MgH}_{2}$, respectively. The reported experimental $\Delta S$ of $\mathrm{Mg}-\mathrm{Al}\left(\mathrm{Mg}_{0.95} \mathrm{Al}_{0.5}\right.$ and $\mathrm{Mg}_{0.9} \mathrm{Al}_{0.1}$ ) are 2.1 and $3.5 \mathrm{Jmol}^{-1} \mathrm{H}_{2} \mathrm{~K}^{-1}$ higher than pure $\mathrm{MgH}_{2}$, respectively. This also supports our computational model applicable.

According to $\mathrm{Eq}$ (19), dehydriding $\Delta S$ increases with the concentration of dissociated $\mathrm{H}$ on the surface of $\mathrm{Mg} / \mathrm{MgH}_{2}$, and hence, increase with the decrease of activation energy for $\mathrm{H}_{2}$ 
dissociation. This is in agreement with our expeimental work on transition metals catalyst covered core-shelled structured Mg-TM systems ${ }^{[11,27]}$. The $\Delta S$ for $\mathrm{Mg}-\mathrm{Ti}, \mathrm{Mg}-\mathrm{V}, \mathrm{Mg}-\mathrm{Nb}$ and Mg-Ni system varies in the order of their activation energy for $\mathrm{H}_{2}$ dissociation theoretical calculating in Pozzo's work ${ }^{[28]}$.

\section{Conclusion}

The effect of modifying $\mathrm{MgH}_{2}$, in terms of nanosizing, forming solid solution and dopping catalysts, on dehydrogenation entropy are calculated by establishing theoretical model. It can be found that the nanosizing results in the decreasing of dehydrogenation $\Delta S$ while forming solid solution and doping catalyst leads to the increase of it. It is predicted that the $\Delta S$ will be less than $120.1 \mathrm{Jmol}^{-1} \mathrm{~K}^{-1}$ when the particle/grain size is reduced to $3 \mathrm{~nm}$. Besides that, the $\Delta S$ would increase along with the increase of solubility of the Mg-based hydrogen storage solid solution alloy. And it also increase with the content of dissociative $\mathrm{H}$ on the hydrides surface, which is affected by catalyzing effect of dopped catalysts. The results of present theoretical model are consistent with the experimental results both from our research and others' report.

\section{Acknowledgements}

This work was supported by the Foundation for Innovative Research Groups of the National Natural Science Foundation of China (No. NSFC51621001), NSFC Project (Nos. 51431001), NSFC Project (Nos. 51471070), the Project Supported by Natural Science Foundation of Guangdong Province of China (2016A030312011 and 2014A030311004), and the Fundamental Research Funds for the Central Universities (Grant No. 20152M058 and No. 2017BQ046). Author Ouyang also thanks Guangdong Province Universities and Colleges Pearl River Scholar Funded Scheme (2014).

\section{References}

[1] W. Grochala, P P. Edwards, Thermal Decomposition of the Non-Interstitial Hydrides for the Storage and Production of Hydrogen, Chemical reviews. 104 (2004) 1283-1316.

[2] A. Züttel, Materials for hydrogen storage, Materials Today.6 (2003) 24-33.

[3] I P. Jain, C. Lal, A. Jain, Hydrogen storage in Mg: A most promising material [J]. International Journal of Hydrogen Energy, Int. J. Hydrogen Energy. 35 (2010) 5133-5144.

[4] B. Bogdanovíć, K. Bohmhammel, B. Christ, Thermodynamic investigation of the magnesium-hydrogen system, J. Alloys Compd.282 (1999) 84-92.

[5] M. Fichtner, Properties of nanoscale metal hydrides, Nanotechnology. 20(2009) 204009

[6] A. Badzian, T. Badzian, E. Brevel, A. Piotrowski, Nanostructured, nitrogen-doped carbon materials for hydrogen storage, Thin Solid Films.398 (2001) 170-174.

[7].J. Vajo, T. Salguero, A. F. Gross, Thermodynamic destabilization and reaction kinetics in light metal 
hydride systems. J. Am. Chem. Soc. 446 (2007) 409-414.

[8] R. W. P. Wagemans, J. H. van Lenthe, P. E. de Jongh, A. J. van Dillen, K. P. de Jong, Hydrogen storage in magnesium clusters: Quantum chemical study, J.Am.Chem.Soc.127 ((2005) 16675-16680.

[9] M. Paskevicius, D. A. Sheppard, C. E. Buckley, J. Am. Chem. Soc. 132, 5077 (2010).

[10] Z. Zhao-Karger, J. Hu, A. Roth, D. Wang, C. Kübel, W. Lohstroh, M.Fichtner, Altered thermodynamic and kinetic properties of $\mathrm{MgH} 2$ infiltrated in microporous scaffold, Chem.Commun. 46 (2010) 8353-8355.

[11] J. Cui, H. Wang, J. W. Liu, L. Ouyang, Q. Zhang, D. Sun, X. Yao, M. Zhu, Remarkable enhancement in dehydrogenation of $\mathrm{MgH} 2$ by a nano-coating of multi-valence Ti-based catalysts, J. Mater. Chem. A. 1 (2013) 5603-5611.

[12] Y.S. Lu, H. Wang, L.Z. Ouyang, J.W. Liu, M. Zhu, Reversible hydrogen storage and phase transformation with altered desorption pressure in Mg90In5Cd5 ternary alloy, J. Alloys Compd. 645 (2015) 103-106.

[13] R. Griessen, N. Strohfeldt, H. Giessen, Thermodynamics of the hybrid interaction of hydrogen with palladium nanoparticles, Nat Mter. 15 (2016) 311-317.

[14] A.Baldi1, T. C. Narayan, A. L. Koh, J. A. Dionne, In situ detection of hydrogen-induced phase transitions in individual palladium nanocrystals, Nat Mter. 13 (2014) 1143-1148.

[15] K.N. Fan, Physical Chemistry. Higher Education Press, Beijing, 2005.

[16] X. Song, J. Zhang, L. Li, K. Yang, G. Liu, Correlation of thermodynamics and grain growth kinetics in nanocrystalline metals, Acta Mater. 54 (2006) 5541-5550.

[17] L.Liu, Q.X. Guo, Isokinetic relationship, isoequilibrium relationship, and enthalpy entropy compensation. Chem. Rev. 101(2001), 673-695.

[18] F.M. Mulder, S.Singh, S. Bolhuis, W.H. Stephan, Extended Solubility Limits and Nanograin Refinement in Ti/ZrFluoride-Catalyzed MgH2, J.Phys. Chem. C, 116(2012), 2001-2012.

[19] V. Bérubé, G.Radtke, M.S.Dresselhaus, Size effects on the hydrogen storage properties of nanostructured metal hydrides: A review, Int. J. Hydrogen Energy. 31 (2007) 637-663.

[20] H.C. Zhong, H. Wang, J.W. Liu, D.L. Sun, M. Zhu, Altered desorption enthalpy of MgH2 by the reversible formation of $\mathrm{Mg}(\mathrm{In})$ solid solution, ScriptaMaterialia. 65 ( 2011) 285-287.

[21] Z.Q. Lan, W.Q. Peng, W.L. Wei, L.Q. Xu, J. Guo, Preparation and hydrogen storage properties of Mg-Al-Li solid solution, Int. J. Hydrogen Energy. 41 (2016) 6134-6138.

[22] A. Andreasen, Hydrogenation properties of Mg-Al alloys, Int J Hydrogen Energ. 33 (2008) 7489-7498.

[23] H.C. Zhong, H. Wang, L.Z. Ouyang, Improving the hydrogen storage properties of $\mathrm{MgH} 2$ by reversibly forming Mg-Al solid solution alloys, Int. J. Hydrogen Energy. 39 (2014) 3320-3326.

[24] F.M. Mulder, S. Singh, S. Bolhuis, S.W.H. Eijt, Extended Solubility Limits and Nanograin Refinement in Ti/Zr Fluoride-Catalyzed $\mathrm{MgH}_{2}$, J. Phys. Chem. C. 116 (2012) 2001-2012.

[25] E. J. Setijadi, X. Li, A. F. Masters, T. Maschmeyer, K. Aguey, Delaminated MoS2 as a structural and functional modifier for $\mathrm{MgH} 2$ e Better hydrogen desorption kinetics through induced worm-like morphologies, Int. J. Hydrogen Energy. 34 (2016), 3552- 3559.

[26] W. Liu, K.F. Aguey, Size effects and hydrogen storage properties of Mg nanoparticles synthesized by an electroless reduction method, J. Mater. Chem. A, 2 (2014), 9718-9126.

[27] J. Cui, J. Liu, H. Wang, L. Ouyang, D. Sun, M. Zhu, X. Yao, Mg-TM (TM: Ti, Nb, V, Co, Mo or Ni) core-shell like nanostructures: Synthesis, hydrogen storage performance and catalytic mechanism, J. Mater. Chem. A. 2 (2014) 9645-9651.

[28] Pozzo M, Dario M, Hydrogen Dissociation and Diffusion on Transition Metal (=Ti, Zr, V, $\mathrm{Fe}, \mathrm{Ru}, \mathrm{Co}, \mathrm{Rh}, \mathrm{Ni}$,Pd ,Cu ,Ag)-doped Mg(0001) Surfaces, Int. J. Hydrogen Energy. 34 (2009) 1922-1930. 
Table 1 Dehydrogenation equilibrium pressure under different temperature, particle size, reaction $\Delta H$ and $\Delta S$ for the reactions of $\mathrm{MgH}_{2} \rightarrow \mathrm{Mg}+\mathrm{H}_{2}$ from different system

Fig. 1 The curve of Grain size/particle size effect on dehydrogenation entropy

Fig. 2 The curve of solid solubility effect on dehydrogenation entropy

Fig. 3 The curve of solid solubility effected on dehydrogenation entropy

Fig. 4 The schematic diagram of dissociated $\mathrm{H}$ atom in different Mg-based systems. a: Pure $\mathrm{Mg}$; b:

Ball-milled $\mathrm{Mg} / \mathrm{MgH}_{2}$ with TM-based catalyst; c: core-shell structured Mg-TM

Table 1 Dehydrogenation equilibrium pressure under different temperature, particle size,reaction $\Delta H$ and $\Delta S$ for the reactions of $\mathrm{MgH}_{2} \rightarrow \mathrm{Mg}+\mathrm{H}_{2}$ from different systems

\begin{tabular}{cccccccc}
\hline $\begin{array}{r}T_{\text {eq }}\left({ }^{\circ} \mathrm{C}\right) \\
\text { Sample ID }\end{array}$ & 250 & 275 & 300 & 325 & 350 & $\begin{array}{c}\text { Particle size } \\
(\mathrm{nm})\end{array}$ & $\begin{array}{c}\Delta H / \Delta S \\
\left(\mathrm{kJmol}^{-1} \mathrm{H}_{2} /\right. \\
\left.\mathrm{Jmol}^{-1} \mathrm{~K}^{-1}\right)\end{array}$ \\
\hline $\mathrm{Mg}-\mathrm{Ti}$ & 0.4160 & 0.9141 & 1.8642 & & & $\sim 800$ & $75.1 / 136.3$ \\
$\mathrm{Mg}-\mathrm{Nb}$ & 0.3777 & 0.8305 & 1.7049 & - & - & $\sim 800$ & $75.1 / 135.5$ \\
$\mathrm{Mg}-\mathrm{V}$ & 0.4109 & 0.9035 & 1.8546 & - & - & & $75.1 / 136.2$ \\
$\mathrm{Mg}-\mathrm{Co}$ & 0.2599 & 0.5708 & 1.1706 & - & - & & $75.0 / 132.2$ \\
$\mathrm{Mg}-\mathrm{Ni}$ & 0.4311 & 0.9480 & 1.9461 & - & - & & $75.1 / 136.6$ \\
$\mathrm{Mg}-\mathrm{Mo}$ & 0.2144 & 0.4709 & 0.9657 & - & - & & $75.0 / 130.6$ \\
$\mathrm{~N}-\mathrm{Mg}$ & - & - & 0.8235 & 1.5888 & 2.9081 & $\sim 40$ & $74.9 / 129.1$ \\
$\mathrm{~B}-\mathrm{MgH}{ }_{2}$ & - & - & 0.8798 & 1.7006 & 3.1179 & $\sim 1000$ & $75.1 / 130.8$ \\
$\mathrm{Refer}[7]$ & - & - & - & - & - & $\sim 7$ & $71.2 / 129.6$ \\
Refer [9] & - & - & - & - & - & $<3$ & $63.85 / 117.2$ \\
Refer [25] & - & - & - & - & - & 17 & $72 / 125$ \\
\hline
\end{tabular}




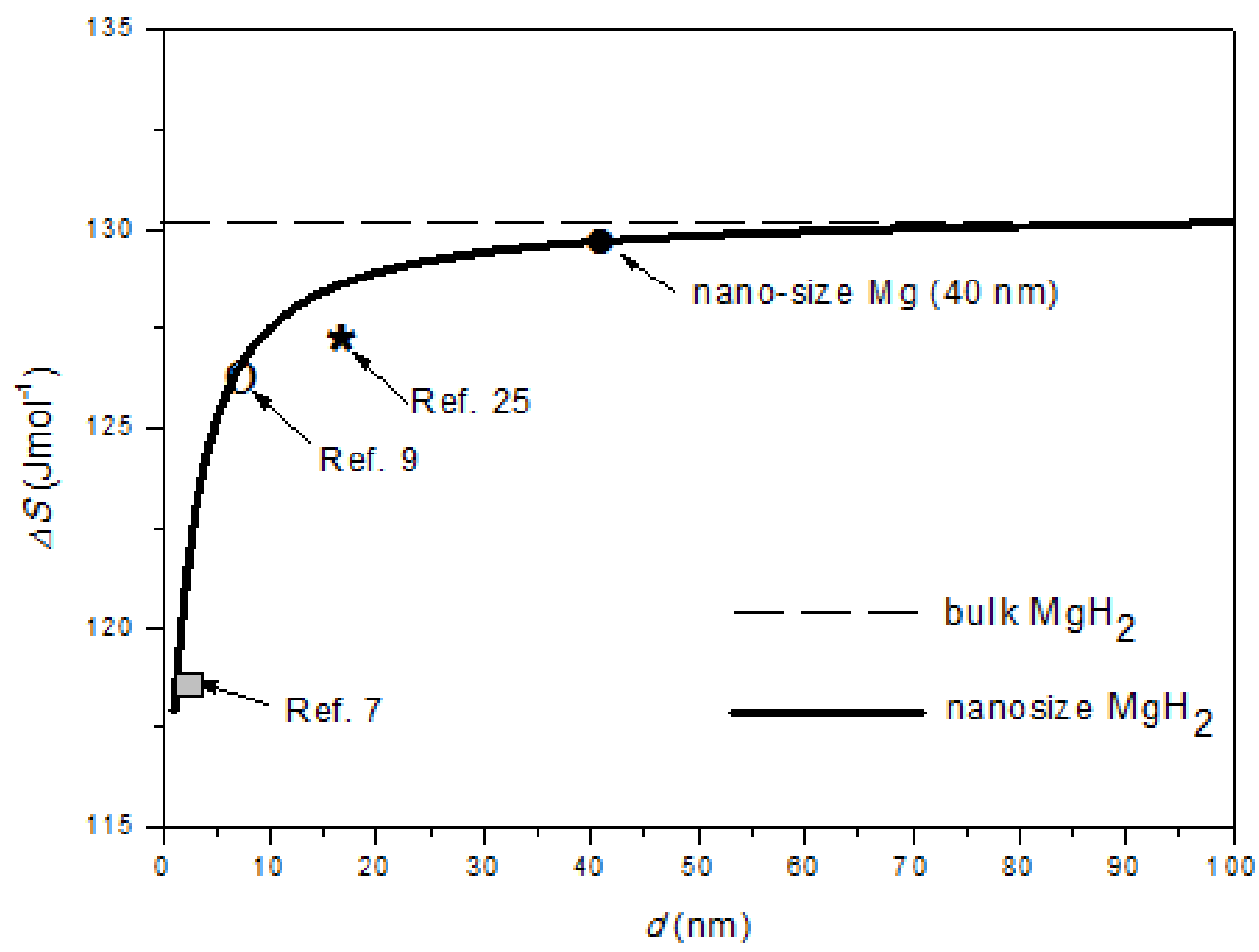

Fig. 1 The curve of Grain size/particle size effect on dehydrogenation entropy

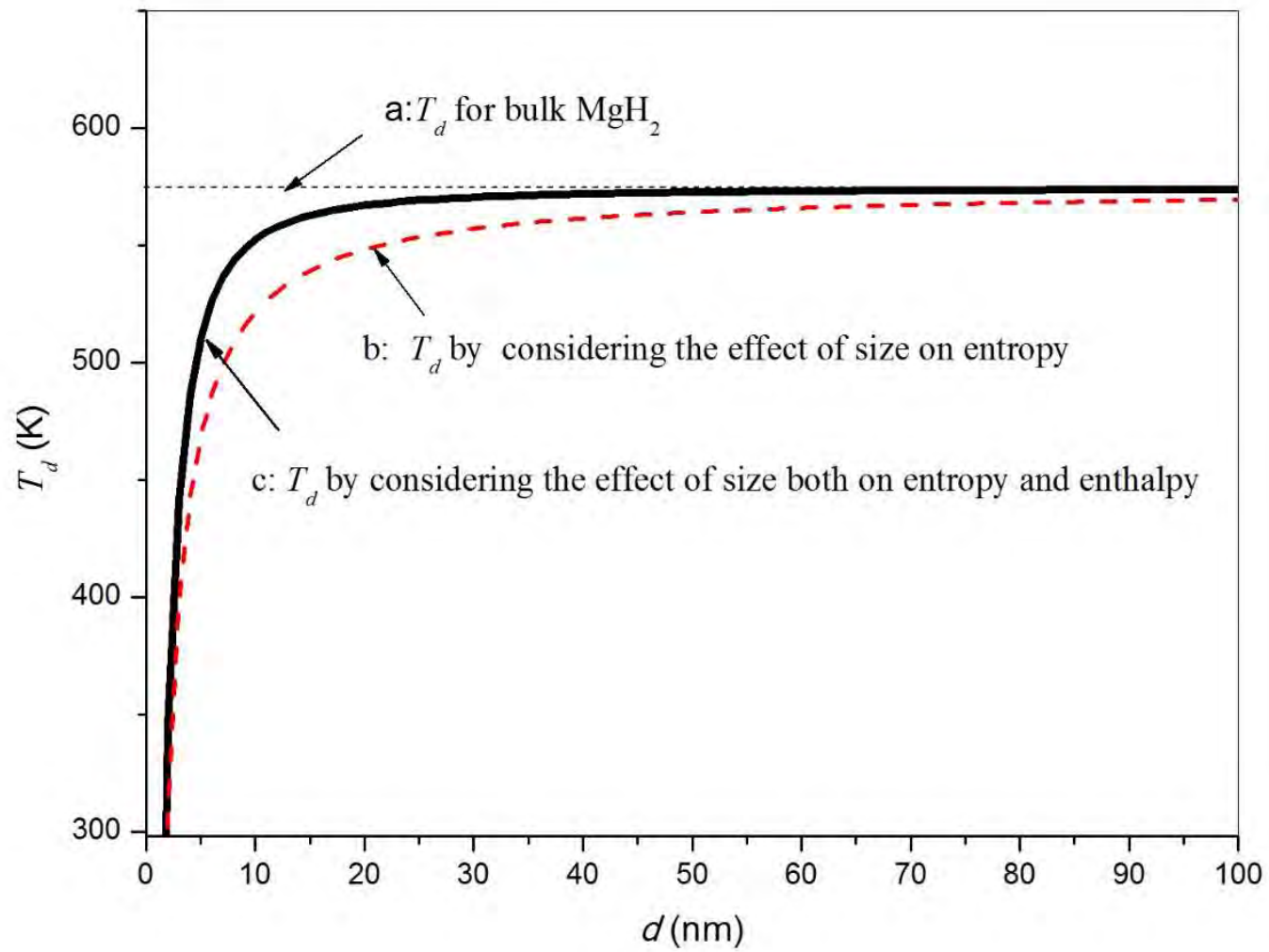

Fig. 2 The curve of dehydrogenation temperature under 1atm depended on grain size/particle size 


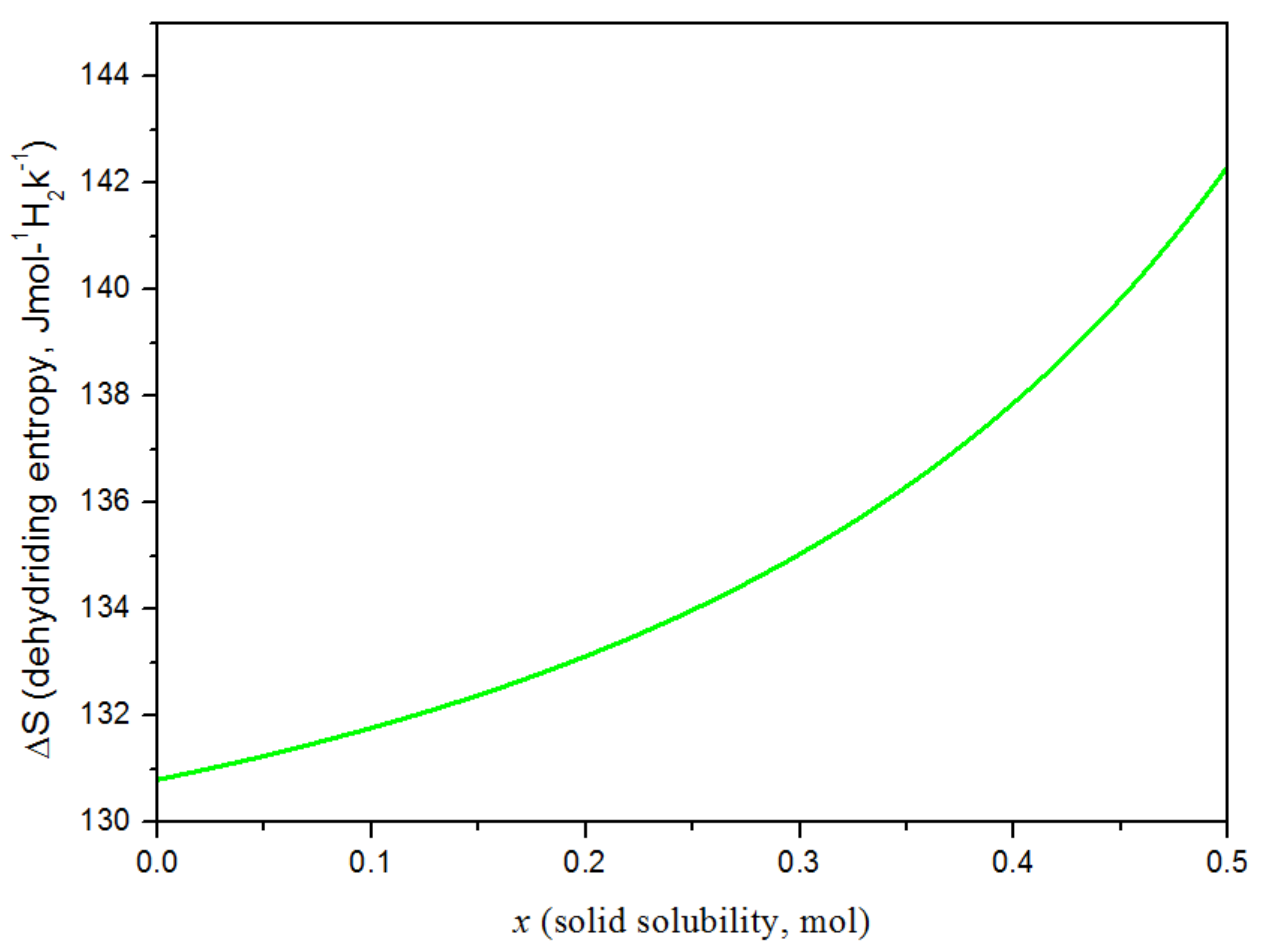

Fig. 3 The effect of solubility on dehydrogenation entropy of Mg based solid solution 
a
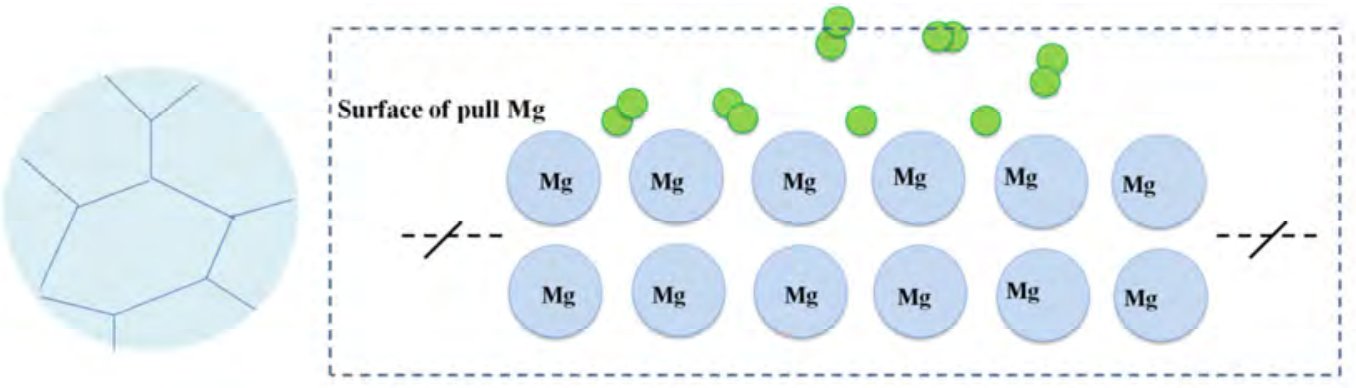

\section{Tm $v_{3} \operatorname{Tm} v_{3}$}

b

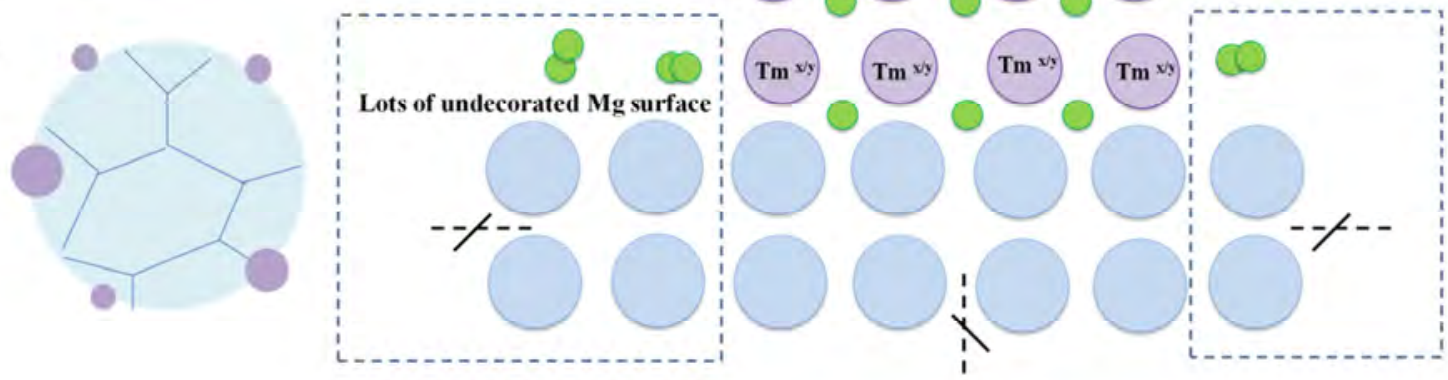

c
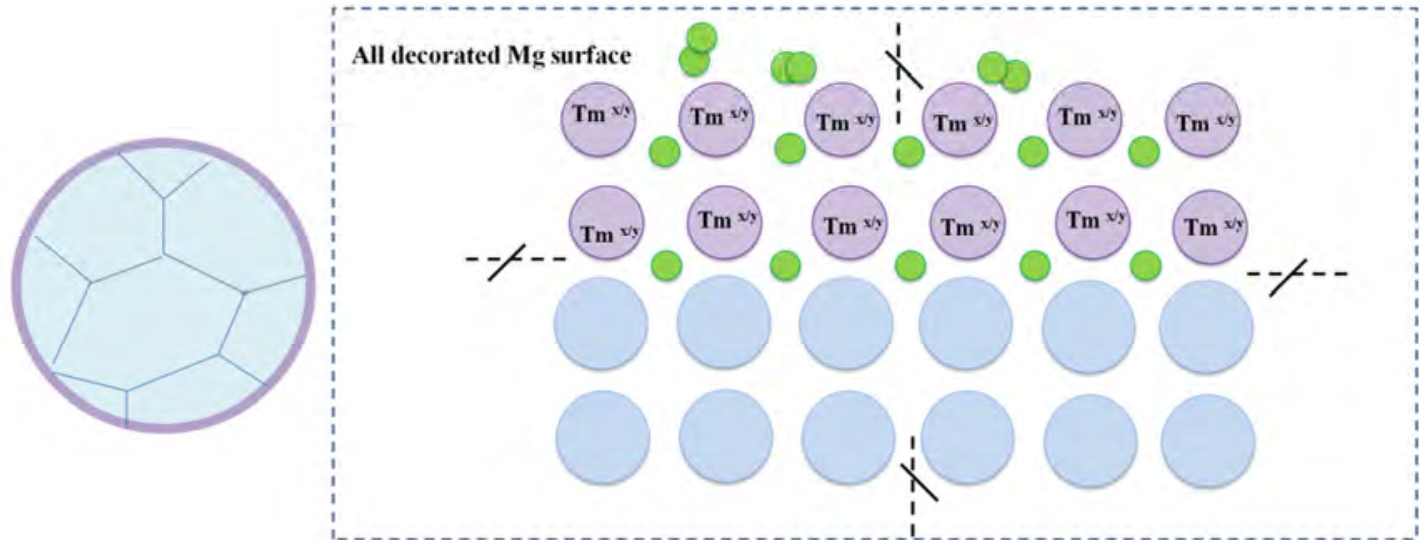

$\mathrm{Mg} / \mathrm{MgH}_{2}=$ TM-based catalysts - Grain boundaries $\mathrm{Mg} / \mathrm{Mg}^{2+} \bigcirc \mathrm{Tm}^{\mathrm{x} / \mathrm{y}} \bigcirc \mathrm{H} \odot \mathrm{H}_{2}$

Fig. 4 The schematic diagram of dissociated $\mathrm{H}$ atom in different $\mathrm{Mg}$-based systems. a: Pure $\mathrm{Mg}$; b: Ball-milled $\mathrm{Mg} / \mathrm{MgH}_{2}$ with TM-based catalyst; c: core-shell structured $\mathrm{Mg}-\mathrm{TM}$ 
Highlights

- A theoretical model is proposed to explain $\Delta S$ change in dehydriding of $\mathrm{MgH}_{2}$.

- The $\Delta S$ value is decreased with the reduction of particle size.

- The $\Delta S$ value is increased with the increased solid solubility of the Mg-based

- The $\Delta S$ value is increased with dissociative $\mathrm{H}$ caused by the doped catalysts.

- The present theoretical model of $\Delta S$ are consistent with the experimental results. 


\section{Accepted Manuscript}

On the hydrogen desorption entropy change of modified $\mathrm{MgH}_{2}$

Jie Cui, Liuzhang Ouyang, Hui Wang, Xiangdong Yao, Min Zhu

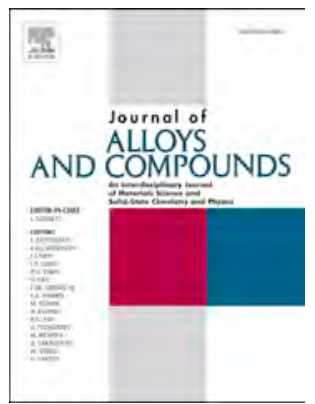

PII:

S0925-8388(17)34107-5

DOI:

10.1016/j.jallcom.2017.11.325

Reference: JALCOM 44018

To appear in: Journal of Alloys and Compounds

Received Date: 28 June 2017

Revised Date: 25 November 2017

Accepted Date: 28 November 2017

Please cite this article as: J. Cui, L. Ouyang, H. Wang, X. Yao, M. Zhu, On the hydrogen desorption entropy change of modified $\mathrm{MgH}_{2}$, Journal of Alloys and Compounds (2017), doi: 10.1016/

j.jallcom.2017.11.325.

This is a PDF file of an unedited manuscript that has been accepted for publication. As a service to our customers we are providing this early version of the manuscript. The manuscript will undergo copyediting, typesetting, and review of the resulting proof before it is published in its final form. Please note that during the production process errors may be discovered which could affect the content, and all legal disclaimers that apply to the journal pertain. 